OPEN ACCESS

Edited by:

Jianbo Xiao,

University of Macau, China

Reviewed by:

Bhekumthetho Ncube,

University of KwaZulu-Natal,

South Africa

Ying Wang,

University of Macau, China

${ }^{*}$ Correspondence:

Nataša P. Ulrih

natasa.poklar@bf.uni-lj.si

Specialty section:

This article was submitted to

Ethnopharmacology,

a section of the journal

Frontiers in Pharmacology

Received: 09 August 2016 Accepted: 16 June 2017

Published: 06 July 2017

Citation:

Ota A and Ulrih NP (2017) An

Overview of Herbal Products and Secondary Metabolites Used

for Management of Type Two

Diabetes. Front. Pharmacol. 8:436.

doi: 10.3389/fphar.2017.00436

\section{An Overview of Herbal Products and Secondary Metabolites Used for Management of Type Two Diabetes}

\author{
Ajda Ota and Nataša P. Ulrih* \\ Department of Food Science and Technology, Biotechnical Faculty, University of Ljubljana, Ljubljana, Slovenia
}

Diabetes mellitus is a common effect of uncontrolled high blood sugar and it is associated with long-term damage, dysfunction, and failure of various organs. In the adult population, the global prevalence of diabetes has nearly doubled since 1980. Without effective prevention and management programs, the continuing significant rise in diabetes will have grave consequences on the health and lifespan of the world population, and also on the world economy. Supplements can be used to correct nutritional deficiencies or to maintain an adequate intake of certain nutrients. These are often used as treatments for diabetes, sometimes because they have lower costs, or are more accessible or "natural" compared to prescribed medications. Several vitamins, minerals, botanicals, and secondary metabolites have been reported to elicit beneficial effects in hypoglycemic actions in vivo and in vitro; however, the data remain conflicting. Many pharmaceuticals commonly used today are structurally derived from natural compounds from traditional medicinal plants. Botanicals that are most frequently used to help manage blood glucose include: bitter melon (Momordica charantia), fenugreek (Trigonella foenum graecum), gurmar (Gymnema sylvestre), ivy gourd (Coccinia indica), nopal (Opuntia spp.), ginseng, Russian tarragon (Artemisia dracunculus), cinnamon (Cinnamomum cassia), psyllium (Plantago ovata), and garlic (Allium sativum). In majority of the herbal products and secondary metabolites used in treating diabetes, the mechanisms of action involve regulation of insulin signaling pathways, translocation of GLUT-4 receptor and/or activation the PPAR $\gamma$. Several flavonoids inhibit glucose absorption by inhibiting intestinal $\alpha$-amylase and $\alpha$-glucosidase. In-depth studies to validate the efficacies and safeties of extracts of these traditional medicinal plants are needed, and large, well designed, clinical studies need to be carried out before the use of such preparations can be recommended for treatment and/or prevention of diabetes. The main focus of this review is to describe what we know to date of the active compounds in these, along with their glucose-lowering mechanisms, which are either through insulin-mimicking activity or enhanced glucose uptake.

Keywords: type 2 diabetes mellitus, antidiabetic activity, herbal products, phenolic compounds, mechanisms of action 


\section{INTRODUCTION}

\section{Diabetes: Definition and Description}

Diabetes mellitus is a group of metabolic diseases that are characterized by hyperglycemia and arise from defects in insulin secretion, insulin action, or both. Chronic hyperglycemia, or raised blood sugar, is a common effect of uncontrolled diabetes, and this is associated with long-term damage, dysfunction, and failure of various organs, especially the eyes, kidneys, nerves, heart, and blood vessels (WHO expert consultation, 2002).

There are two main types of diabetes, which are characterized by progressive $\beta$-cell death. Type 1 diabetes was previously known as insulin-dependent, juvenile or childhood-onset diabetes, and it is characterized by deficient insulin production that requires daily administration of insulin. This results from cellular-mediated autoimmune destruction of the $\beta$-cells of the pancreas. Type 2 diabetes was previously known as noninsulin-dependent or adult-onset diabetes, and it results from the ineffective use of insulin by the body. Several risk factors are known to be involved in the development of type 2 diabetes, including: genetic factors (i.e., family history), obesity, poor diet, insufficient physical activity, advancing age, ethnicity, high blood glucose during pregnancy, hypertension, and dyslipidemia (Newman et al., 1987; Kaprio et al., 1992; Matsuda and Kuzuya, 1994; Chehade et al., 2013).

Gestational diabetes represents a third class of diabetes, and this arises from glucose intolerance, with an onset during pregnancy. Women with gestational diabetes are at an increased risk of complications during pregnancy and at delivery. Although gestational diabetes is a temporary condition, it carries a longterm risk of type 2 diabetes (Bellamy et al., 2009).

According to the World Health Organization, an estimated 422 million adults were living with diabetes in 2014. In the adult population, the global prevalence of diabetes has nearly doubled since 1980. Over the past decade, diabetes prevalence has risen more rapidly in low-income and middle-income countries than in high-income countries. Diabetes caused 1.5 million deaths in 2012, with hyperglycemia causing an additional 2.2 million deaths, as it is associated with increased risk of cardiovascular and other diseases. Although separate global estimates of diabetes prevalence for type 1 and type 2 diabetes are not available, the majority of people with diabetes are affected by type 2 diabetes. Also of concern is that previously type 2 diabetes was diagnosed almost entirely among adults, while now it also occurs in children (WHO, 2016). Without effective prevention and management programs, further significant rises in diabetes will have grave consequences on the health and lifespan of the world population (International Diabetes Federation, 2013).

Oxidative stress is an acknowledged pathogenic mechanism in the development and progression of diabetes and its complications, which can arise as a result of increased free radical production and impaired antioxidant defenses (Ceriello, 2000; Maritim et al., 2003; King and Loeken, 2004; Vos et al., 2012). There are several known mechanisms whereby hyperglycemia contributes to the pathogenesis of diabetic complications: non-enzymatic glycosylation of proteins and lipids; protein kinase $\mathrm{C}$ activation; activation of the polyol pathway; and auto-oxidation of glucose (Baynes and Thorpe, 1999; Ceriello, 2000; Maritim et al., 2003; Aronson, 2008).

Oxidative stress and other stresses caused by overnutrition (endoplasmic reticulum stress, lipotoxicity, and glucotoxicity) are thought to induce inflammatory response that plays an important role in the pathogenesis of type 2 diabetes (Shoelson et al., 2006; Donath and Shoelson, 2011; Ye and Driver, 2016). Recent studies have also shown the pathological involvement of the immune system in type 2 diabetes, that is, based on the presence of autoantibodies against $\beta$ cells, selfreactive $\mathrm{T}$ cells and evidence of beneficial effect of some antiinflammatory and immunomodulatory therapy, being viewed as an autoinflammatory disease (Itariu and Stulnig, 2014). Nutritional interventions with food supplements as a form of complementary therapy in patients with diabetes are being used increasingly to counter these effects (Shane-McWhorter, 2005; Campbell, 2010; Ho et al., 2013; Facchinetti et al., 2014). In this review, botanicals that are most frequently promoted to help manage blood glucose levels and can be found marketed as food supplements promoting antidiabetic activity were selected and their mechanism of action described.

\section{Food Supplements in Diabetes}

Food supplements are concentrated sources of nutrients or other substances that can have nutritional or physiological effects, where the purpose is to supplement the normal diet. Food supplements are marketed in "dose" forms, such as pills, tablets, capsules, and liquids in measured doses. Supplements can be used to correct nutritional deficiencies or to maintain adequate intake of certain nutrients. However, in some cases excessive intake of vitamins and minerals might be harmful or cause unwanted side effects; therefore, indications for their maximum levels are necessary to ensure their safe use in food supplements (EFSA, 2015b). Recently, antioxidants have been extensively used to counter or overcome the effects of excess reactive oxygen species, which are involved in several pathologies, including diabetes and obesity. Another therapeutic approach for treating type 2 diabetes is the use of phytochemicals to lower the glucose absorption by inhibiting intestinal carbohydrate-hydrolysing enzymes $\alpha$-amylase and $\alpha$-glucosidase (Sales et al., 2012; Shori, 2015). Several phytochemicals were also been reported to reduce inflammatory compounds involved in the pathology of type 2 diabetes.

\section{HERBAL PRODUCTS AND SECONDARY METABOLITES}

\section{Herbal Products with Hyperglycemic Actions}

Botanicals have been used for medicinal purposes through much of human history (Petrovska, 2012). Botanicals and their derived preparations made from plants, algae, fungi, and lichens have become widely available on the EU market in the form of food supplements (EFSA, 2015a). 
Many pharmaceuticals commonly used today are structurally derived from the natural compounds that are found in traditional medicinal plants. For example, the development of the antihyperglycemic drug metformin can be traced to the traditional use of Galega officinalis to treat diabetes (Evans and Bahng, 2014). Botanicals that are most frequently promoted to help manage blood glucose levels include bitter melon (Momordica charantia), fenugreek (Trigonella foenum graecum), gurmar (Gymnema sylvestre), ivy gourd (Coccinia grandis), nopal (Opuntia spp.), ginseng, Russian tarragon (Artemisia dracunculus), cinnamon (Cinnamomum cassia), psyllium (Plantago ovata), and garlic (Allium sativum) (Cefalu et al., 2008).

\section{Bitter Melon (M. charantia L.)}

Momordica charantia is a climbing plant that belongs to the family Cucurbitaceae and is commonly known as bitter gourd or bitter melon. All parts of the plant have a bitter taste, including the fruit, which have a warty texture that resembles a small cucumber. M. charantia is cultivated throughout the tropics and subtropics (Grover and Yadav, 2004). The main phytochemical constituents of bitter melon that have reported hypoglycemic actions are the cucurbitane-type triterpenoids charantin (a steroidal glycoside that is an equal mixture of stigmasterol glucoside and $\beta$-sitosterol glucoside), karaviloside IX, momordicoside $\mathrm{S}$ and its aglycones momordicosides $\mathrm{A}, \mathrm{B}$, $\mathrm{Q}, \mathrm{R}$, and $\mathrm{T}$, and also polypeptide- $\mathrm{p}$, vicine, and the ribosomeinactivating protein momordin (Tan et al., 2008; Joseph and Jini, 2013). Several mechanisms of action have been proposed for the hypoglycemic actions of bitter melon extracts. Studies have shown that these can inhibit intestinal absorption of glucose (Grover and Yadav, 2004; Chaturvedi, 2012), suppress key glucogenic enzymes (Shibib et al., 1993), and decrease hepatic gluconeogenesis (Tsai et al., 2012). It has been proposed that $M$. charantia enhances the activity of the AMP-activated protein kinase (AMPK) pathway (which is an important cellular regulator of lipid and glucose metabolism), and reduces expression of phosphoenolpyruvate carboxykinase (PEPCK; which results in reduced glucose levels; Shih et al., 2014). Polypeptide-p is sometimes referred as "plant insulin," and it is one of the few of these active compounds that have been studied in clinical trials. Polypeptide-p consists of 166 amino-acid residues and closely resembles bovine insulin (Khanna et al., 1981; Efird et al., 2014). Polypeptide-p is a very effective hypoglycemic agent when administered subcutaneously (Joseph and Jini, 2013). Clinical study investigating the effect of subcutaneous injection of polypeptide-p resulted in a statistically significant drop in mean blood sugar levels (Baldwa et al., 1977). Recent study demonstrated that administration of a cucurbitane-type triterpenoid isolated from $M$. charantia named compound K16 reduced blood glucose and blood lipids in murine model, while improving glucose tolerance. Compound K16 also upregulated the expression of several of insulin signaling pathway-associated proteins (Jiang et al., 2016). Only a few randomized controlled trials of bitter melon have been conducted. According to Efird et al. (2014) out of 21 reviewed studies less than $20 \%$ received a quality score of two or greater on the Jadad scale. Although evidence suggests possible beneficial effects of extracts of bitter melon and its active compounds in the prevention and control of diabetes, future clinical studies are needed to confirm this.

\section{Fenugreek (T. foenum graecum L.)}

Fenugreek is a plant of the Fabaceae family that is native to India, China, and North Africa (Prabhakar and Doble, 2011). The most studied bioactive compounds from fenugreek with reported hypoglycemic actions are diosgenin (3b-hydroxy-5-spirostene), 4-hydroxyisoleucine (Figure 1), and the soluble dietary fiber fraction of fenugreek seeds (Fuller and Stephens, 2015).

Diosgenin in fenugreek is a major aglycone of saponin, and the reported hypoglycemic mechanisms of its action include renewal of pancreatic $\beta$-cells and stimulation of insulin secretion (Kalailingam et al., 2014), antioxidative effects (Son et al., 2007), and promotion of adipocyte differentiation and enhancement of insulin-dependent glucose uptake (Uemura et al., 2010). 4Hydroxyisoleucine is a branched-chain amino-acid derivative that is only found in plants, and it represents the majority of the total content of free amino acids in fenugreek seeds (Fuller and Stephens, 2015). It has been shown that the insulinotropic and antidiabetic properties of 4-hydroxyisoleucine act through stimulation of glucose-dependent insulin secretion and reduction of insulin resistance in muscle and/or liver (Jetté et al., 2009). Fenugreek seeds are also a rich source of fiber (50-65 g fiber/100 g seeds). The soluble dietary fiber fraction of fenugreek (i.e., galactomannan) has been shown to enhance glycemic control. This effect has been attributed to inhibition of lipid-hydrolyzing

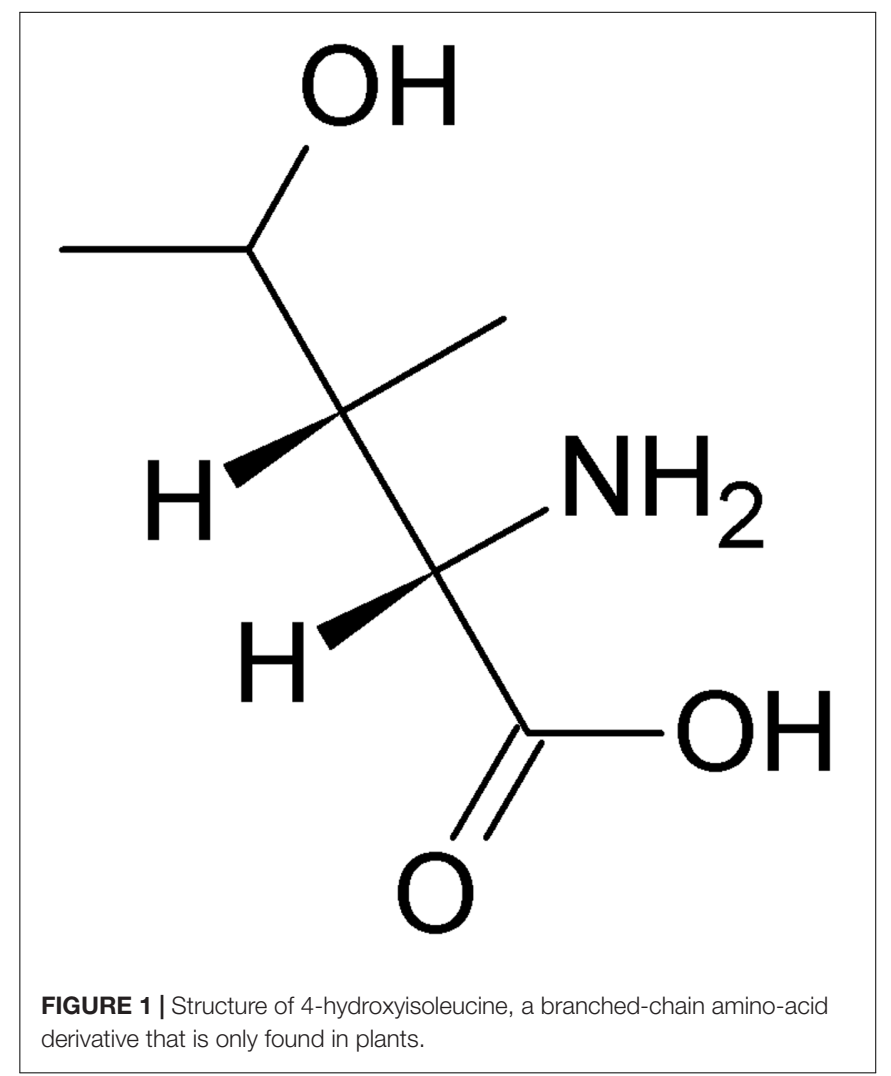


and carbohydrate-hydrolyzing enzymes in the digestive system (Hannan et al., 2007). Galactomannan also reduces the rate of glucose uptake through its actions as a significant physical barrier to glucose diffusion (Srichamroen et al., 2009). Clinical studies reported that intake of fenugreek seeds significantly changed fasting blood glucose, $2 \mathrm{~h}$ postload glucose and hemoglobin A1c (HbA1c; Neelakantan et al., 2014). Results of a recent study conducted on men and women with prediabetes strongly suggests that the enhancement of insulin levels is due to insulinotropic effect of fenugreek and suggest that the mode of action is a result of alkaloids present (Gaddam et al., 2015). Although results from clinical trials support beneficial effects of fenugreek seeds on glycemic control in persons with diabetes, trials with better methodology quality and well characterized preparation of sufficient dose are needed to provide more conclusive evidence. With its hypoglycemic and antidyslipidemic effects, fenugreek represents an attractive new candidate for treatment of type 2 diabetes, obesity, and dyslipidemia, the key components of metabolic syndrome.

\section{Gurmar [G. sylvestre (Retz.) R.Br. ex Sm.]}

Gymnema sylvestre is a large woody climbing plant that grows in the dry forests of India. In Hindu folklore, chewing gymnema leaves results in the inability to taste sweetness. It is therefore also known as "gurmar," which means "destroyer of sugar" in Hindi (Yeh et al., 2003). The active compounds that can be extracted from this plant are the gymnemic acids, of which there are several (gymnemic acids I-VII, gymnemosides A-F; Tiwari et al., 2014) and the gymnemasaponins (Leach, 2007; Khramov et al., 2008). Another compound with sugar suppression activity that has been isolated from G. sylvestre is gurmarin, a 35-amino-acid peptide (Imoto et al., 1991). The atomic arrangement of gymnemic acids on the taste buds are similar to that of sugar molecules, and therefore their binding to the receptors on the taste buds prevents receptor activation by the sugar molecules in the food, which prevents the taste of sweetness.

The proposed mechanisms for the hypoglycemic action of gymnemic acids might be increased secretion of insulin from the pancreas and promotion of islet cell regeneration (Baskaran et al., 1990). Gymnemic acids can also delay glucose absorption in the blood and prevent absorption of sugar molecules by the intestine, which leads to reductions in blood sugar levels (Tiwari et al., 2014). Although several studies have reported antidiabetic effects and sugar inactivation properties of gurmar (Kumar et al., 2014; Li et al., 2015; Kamble et al., 2016), and recent interventional, randomized, double blind clinical study (NCT02370121) reported statistically significant reduction in body weight, reduced BMI and lower values for VLDV (ClinicalTrials.gov, 2016), clinical approval and scientific validation remain necessary before its use can be approved in the treatment of patients with diabetes.

\section{Ivy gourd [C. grandis (L.) Voigt, syn. Coccinia indica Wight \& Arn.]}

Ivy gourd (C. grandis) is a perennial creeper that belongs to the Cucurbitaceae family. It has been traditionally used in Ayurvedic practice as an antidiabetic drug. The proposed mechanism of action of C. grandis is not well understood, although it appears to be an insulin mimetic (Kamble et al., 1998). Extracts of C. grandis are believed to have hypoglycemic effects through an insulin-secreting effect or through an influence on the enzymes involved in glucose metabolism (Patel et al., 2012). Despite the broad use of $C$. grandis in traditional medicine, very few systematic clinical studies have been reported to date that have examined its therapeutic properties. Human trials have shown that the active components of a $C$. grandis extract can reduce elevated levels of the enzymes glucose-6-phosphatase and lactase dehydrogenase in the glycolytic pathway, and restore lipoprotein lipase activity in the lipolytic pathway, with the control of hyperglycemia in diabetes (Hossain et al., 1992; Kamble et al., 1998; Kuriyan et al., 2008). Double-blind clinical trial conducted on 61 healthy individuals showed statistically significant difference in postprandial blood sugar levels after 1 and $2 \mathrm{~h}$ confirming a blood sugar lowering effect of C. grandis (Munasinghe et al., 2011). The data from animal and human trials are promising, and the reported hypoglycemic action of C. grandis might indicate its use as a dietary adjunct in the treatment of patients with diabetes.

\section{Nopal (Opuntia spp.)}

The genus Opuntia is commonly known as prickly pear cactus, and this includes species that produce the nutritious fruit and young, edible cladodes (stem pads) that have been used for both nourishment and medicine for hundreds of years (GonzálezStuart, 2013; Cota-Sánchez, 2016). The prickly pear cactus is traditionally used to treat diabetes in the form of a blended "shake" that is prepared from young cladodes (Becerra-Jiménez and Andrade-Cetto, 2012). Nopal is rich in highly soluble fiber and pectin, which can affect intestinal glucose uptake, thus partly explaining its hypoglycemic actions (Frati et al., 1990; Evans and Bahng, 2014). Several studies have confirmed that a total extract and a juice from the plant can have antihyperglycemic effects (Ibañez-Camacho et al., 1983; Becerra-Jiménez and AndradeCetto, 2012). Data from animal studies using extracts without fiber and pectin that have shown antihyperglycemic actions have suggested additional modes of action (Trejo-González et al., 1996; Andrade-Cetto and Wiedenfeld, 2011). Polysaccharide ODP-Ia has been isolated from Opuntia dillenii Haw., and this was shown to have antihyperglycemic effects through the protection of the liver from peroxidation damage and through the maintenance of tissue function, thereby improving the sensitivity of target cells to insulin (Zhao et al., 2011). Recent study conducted on murine model suggested that Opuntia ficus-indica treatment acts by inhibiting glucose absorption from the intestine and enhancing glucose uptake from insulin-sensitive muscle cells through the AMPK/p38 MAPK signaling pathway (Leem et al., 2016). Findings of a recent study conducted on Mexican patients with type 2 diabetes suggest that $O$. ficus-indica (L.) Mill. could reduce postprandial blood glucose and serum insulin, as well as increase antioxidant activity in healthy people and patients with type 2 diabetes (López-Romero et al., 2014). Although preliminary human and animal trials have suggested that certain Opuntia species have hypoglycemic properties, more clinical studies are necessary to determine the true benefits of these plants 
as botanical interventions in the treatment of patients with type 2 diabetes.

\section{Ginseng: Korean or Asian ginseng (Panax ginseng C.A. Mey.) and American ginseng (Panax quinquefolius L.)}

Out of 14 identified ginseng species to date, Korean red ginseng (P. ginseng) and American ginseng (P. quinquefolius) have been the most extensively used and studied (Christensen, 2009). The part of the plant that is mainly used for medicinal purposes is the roots, although other parts are also being investigated for antidiabetic effects (Xie et al., 2002; Dey et al., 2003). The active components in ginseng include polysaccharides and polyacetylenes, although the majority of its pharmacological activity has been attributed to the ginsenosides, a group of triterpenoid saponins (Christensen, 2009; Wee et al., 2011). Indeed, more than 150 naturally occurring ginsenosides have been isolated from the roots, leaves, stems, fruit, and flower heads of various Panax species (Christensen, 2009). Several clinical trials and animal studies have demonstrated that ginseng and ginsenosides can lower blood glucose, to increase insulin sensitivity and regulate lipid metabolism (Cho et al., 2006; Vuksan et al., 2008). The proposed mechanism of the modulation of metabolic processes by ginsenosides is their activation of the peroxisome proliferator-activated receptors (PPARs) that regulate glucose and lipid metabolism, and the transcription of proteins involved in glucose and fatty-acid uptake (Auwerx et al., 1996). Recent studies have shown that ginsenosides activate AMPK pathway, resulting in suppression of hepatic gluconeogenesis and steatosis (Gui et al., 2016). Additional potential health effects of ginsenosides include anticarcinogenic, immunomodulatory, anti-inflammatory, antiallergic, anti-atherosclerotic, antihypertensive, and antidiabetic effects, as well as effects on the central nervous system (Christensen, 2009). Meta-analysis of 16 randomized controlled trials in people with and without diabetes concluded that ginseng modestly yet significantly improved fasting blood glucose in people with and without diabetes (Shishtar et al., 2014). For better assessment of ginseng's anti-diabetic efficacy, larger and longer randomized controlled clinical studies, using standardized ginseng preparations are warranted.

\section{Russian tarragon (A. dracunculus L.)}

Artemisia dracunculus L., or Russian tarragon, is a perennial herb from the Asteraceae (daisy) family. French tarragon (which is also known as German tarragon) and Russian tarragon are the two main reported cultivars for this species (Obolskiy et al., 2011). A. dracunculus has been widely used in traditional medicine because of its potential antimicrobial and antioxidant activities (Lopes-Lutz et al., 2008; Ahameethunisa and Hopper, 2010). The most important groups of biologically active secondary metabolites in A. dracunculus essential oils are coumarins, flavonoids, and phenolic acids (Obolskiy et al., 2011). Several studies have reported antidiabetic effects of $A$. dracunculus (Govorko et al., 2007; Kheterpal et al., 2014; Ribnicky et al., 2014; Aggarwal et al., 2015). A study by Aggarwal et al. (2015) demonstrated that a well-characterized extract of $A$. dracunculus
L. known as PMI-5011 can trigger insulin release from primary $\beta$-cells, as well as protect $\beta$-cells, which contributes to the preservation of metabolic homeostasis of insulin and $\beta$-cells. It has also been shown that PMI-5011 promotes decreased glucose and insulin levels in animal models and improves insulin signaling in primary human skeletal muscle cells (Kheterpal et al., 2014; Obanda et al., 2014; Vandanmagsar et al., 2014). PMI5011 treatment also led to an inhibition of cytokine-induced activation of inflammatory signaling pathways (Vandanmagsar et al., 2014). Anti-inflammatory effect of ethanol extract was also demonstrated in murine model (Eidi et al., 2016). These data indicate that this PMI-5011 A. dracunculus L. extract represents a promising botanical treatment for patients with diabetes. The most recent randomized, double blind, placebocontrolled clinical trial (NCT02330341) evaluating the effect of A. dracunculus on glycemic control, insulin sensitivity, and insulin secretion in patients with impaired glucose tolerance reported significantly decreased systolic blood pressure, glycated HbA1c, area under the curve of insulin, and total insulin secretion with a significant increase in HDL-C levels (Méndez-del Villar et al., 2016).

\section{Cinnamon (Cinnamomum spp.)}

Cinnamomum (cinnamon) is a genus of the Lauraceae family. To date, about 250 species of cinnamon have been identified (Medagama, 2015). Several preclinical and clinical investigations have demonstrated that extracts of cinnamon species can have antidiabetic activities, and have investigated their mechanism of action (Akilen et al., 2012; Chen et al., 2012; Cheng et al., 2012; Verspohl et al., 2005). The procyanidin oligomers are thought to be responsible for the antidiabetic activity of cinnamon (Lu et al., 2011; Chen et al., 2012). The mechanism behind the antidiabetic actions of cinnamon species is not fully understood yet. Different hypoglycemic effects have been reported for different cinnamon species. Chen et al. (2012) reported that a C. cassia extract can promote lipid accumulation in adipose tissue and liver, whereas a Cinnamomum tamala (Buch.-Ham.) T. Nees \& C.H. Eberm. extract mainly improved the insulin concentrations in the blood and pancreas. They defined the different antidiabetic effects according to the diverse procyanidin oligomer components in these extracts (Chen et al., 2012). Improved insulin resistance and lipid metabolism have been reported for a water extract of cinnamon, which was believed to be through activation of PPARs (Sheng et al., 2008). Decreased gene expression of two major regulators of hepatic gluconeogenesis has been reported for a cinnamon water extract (i.e., PEPCK and glucose-6phosphatase), as also reported for a murine model (Cheng et al., 2012). Cinnamon also contains anti-inflammatory compounds that reduce production of prostaglandin-E2, interleukin 6 and nitric oxide (NO). Trans-cinnamaldehyde exhibited the strongest activity on NO production (Tung et al., 2008). A study on rat model of gestational diabetes showed hypoglycemic action of cinnamaldehyde by increasing insulin secretion and sensitivity through activating the antioxidant defense system, suppressing pro-inflammatory cytokines production and upregulating PPAR $\gamma$ gene expression (Hosni et al., 2017). Review of clinical trials, evaluating the experimental evidence available 
for cinnamon in improving glycemic targets concluded that cinnamon has the potential to be a useful add-on therapy in the managing type 2 diabetes, but further trials are needed to establish its efficacy and safety (Medagama, 2015). Data from different animal and human studies warrant continued investigations into the benefits of different cinnamon extracts supplementation on the prevention and treatment of type 2 diabetes and gestational diabetes.

\section{Garlic (A. sativum L.)}

Garlic (A. sativum) is a member of the Amaryllidaceae family, along with onions, chives, and shallots (Iciek et al., 2009). In addition to promoting total antioxidant levels and catalase activity, the antidiabetic potential of garlic includes: hyperinsulinemia, hypoglycemia, hypocholesterolemia, hypotriglyceridemia, and anti-glycation and anti-lipidperoxidation actions (Thomson et al., 2016). The active ingredients of garlic that have been attributed to its beneficial effects are mainly volatile sulfur compounds, like alliin (Figure 2), allicin, diallyl disulfide, diallyl trisulfide, diallyl sulfide, $S$-allyl cysteine, ajoene, and allyl mercaptan (Padiya and Banerjee, 2013; Bayan et al., 2014).

Both fresh and aged garlic and its bioactive compounds have been extensively studied for their antihyperglycemic actions both in experimentally induced and genetic animal models of diabetes (Padiya et al., 2011; Shiju et al., 2013; Al-Qattan et al., 2016; Sathibabu Uddandrao et al., 2016; Thomson et al., 2016) and in human studies (Ashraf et al., 2011; Atkin et al., 2016). Garlic has been shown to improve insulin sensitivity and the associated metabolic syndrome in animal models (Padiya et al., 2011). Clinical trial studying the effect of oral administration of raw garlic on type 2 diabetic patients showed a significant reduction in blood glucose level, lipid metabolism and significant improvement in superoxide dismutase, catalase, and glutathione peroxidase in erythrocytes of diabetic patients (Mirunalini et al., 2011). Several studies have also reported increased insulin secretion upon administration of garlic or garlic extracts/preparations (Eidi et al., 2006; Liu et al., 2006). Islam and Choi (2008) speculated that the higher insulin production is a result of the actions of allixin, $S$-allyl cysteine sulfoxide, and diallyl trisulfide. Recent studies of $S$-allyl cysteine, the main organosulfur bioactive molecule in aged garlic extract,

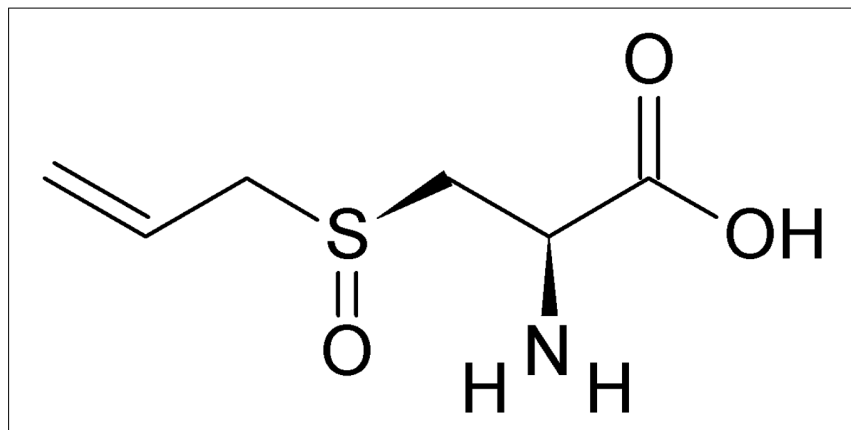

FIGURE 2 | Structure of alliin. demonstrated its anti-diabetic, antioxidant, anti-inflammatory and neuroprotective properties (Baluchnejadmojarad et al., 2017; Zarezadeh et al., 2017). Studies in animal models and preliminary human studies have indicated beneficial effect of garlic and garlic extracts in the treatment of patients with diabetes and related metabolic disorders; however, more clinical trials are warranted to further explore the benefits of garlic for patients with type 2 diabetes.

\section{Psyllium (P. ovata Forssk.)}

Plantago spp. belongs to the Plantaginaceae family, which comprises approximately 275 annual and perennial species that are distributed throughout the world. Some species are particularly valuable in the nutraceutical and pharmaceutical industries due to the mucilaginous product that is derived from the seed husk, which is known as psyllium (Gonçalves and Romano, 2016). The most abundant polysaccharide in psyllium are the heteroxylans (Thakur and Thakur, 2014). Preparations obtained from seed husks of $P$. ovata are an excellent source of soluble fiber (Moreno et al., 2003). As psyllium is less readily fermented, it causes fewer abdominal problems and it is better tolerated than other fiber supplements (Pal and RadavelliBagatini, 2012). The proposed glucose-lowering mechanisms of psyllium are: slowed access of glucose to the small intestine; delayed gastric emptying; and actions on carbohydrate digestion and absorption (Pastors et al., 1991; Anderson et al., 1999). Clinical study evaluating the effects of psyllium in type 2 diabetic patients reported significant decrease of glucose absorption and reduction of total and LDL cholesterol in the presence of psyllium, indicating its beneficial therapeutic effect in the metabolic control of type 2 diabetics (Sierra et al., 2002).

\section{Ginger (Zingiber officinale Roscoe)}

Ginger belongs to Zingiberaceae family and its rhizome is widely used as a spice all over the world. It has been traditionally used as herbal medicine to treat cancer, rheumatism, toothache, digestive health, and diabetes (Park and Pezzuto, 2002; Ali et al., 2008). Its components gingerols, shogaols, paradols, and zingiberene exhibit antioxidative effect, glucose and lipid lowering effects, as well as immunomodulatory, anti-inflammatory, antiapoptosis effect (Jolad et al., 2004; Ali et al., 2008; Arablou et al., 2014). The anti-inflammatory action of ginger is attributed to gingerols, shogaols, and diarylheptanoids that are thought to inhibit the activity of cyclooxygenase, inducible NO synthase and lipoxygenase suppress prostaglandin synthesis and interfere in cytokine signaling. Recent study reported improved insulin sensitivity and reduced total cholesterol and triglycerides as well as reduced C-reactive protein and prostaglandin E2 in patients with type 2 diabetes (Arablou et al., 2014). A doubleblind, placebo-controlled, randomized clinical trial conducted on patients with type 2 diabetes who did not receive insulin showed that ginger supplementation significantly reduced serum triglyceride and reported a minor beneficial effect on serum glucose (Shidfar et al., 2015).

Different studies revealed more than 100 plant species generally used for treatment of diabetes (Chauhan et al., 2010; Eddouks et al., 2014; Mamun-or-Rashid et al., 2014). The 
majority of the experiments confirmed their beneficial effect in the management of diabetes mellitus. Among the plants used for the diabetes, the most commonly studied species are described above, while other common plants used to treat diabetes that are available everywhere and their active phytochemicals are reported in Table 1.

\section{Secondary Metabolites \\ Plant Polyphenols}

Polyphenols are a large and heterogeneous group of phytochemicals that can be found in plant-based foods, such as tea, coffee, wine, cocoa, cereal grains, legumes, fruit, and berries (Hanhineva et al., 2010). Polyphenols are divided into flavonoids, phenolic acids, stilbenes, and lignans. Flavonoids can be further divided into flavones, flavonols, flavanols, flavanones, isoflavones, and anthocyanins (Manach et al., 2004). Evidence from numerous animal studies support antidiabetic properties for some of the dietary polyphenols, which suggests their potential for prevention and management of type 2 diabetes (Kim et al., 2016). Several mechanisms might contribute to their hypoglycemic effects, including: inhibition of carbohydrate digestion and glucose absorption in the intestine; stimulation of insulin secretion from pancreatic $\beta$-cells; modulation of glucose release from the liver; activation of insulin receptors and glucose uptake in insulin-sensitive tissues; and modulation of intracellular signaling pathways and gene expression (Hanhineva et al., 2010; Bahadoran et al., 2013).

\section{Resveratrol}

Resveratrol $\left(3,5,4^{\prime}\right.$-trihydroxy-trans-stilbene) is a phytoalexin that is naturally synthesized by plants as a defense mechanism that is triggered in response to infection and injury by fungi, bacteria, UV irradiation, and other plant stresses (Park and Pezzuto, 2015). Resveratrol is found in berries, grape skins, red

TABLE 1 | List of most common plants and their active phytochemicals having antidiabetic activity.

\begin{tabular}{|c|c|c|}
\hline Medicinal plant & Active phytochemical(s) & Reference \\
\hline Aegle marmelos & Aegelin, coumarins, alkaloids & Chauhan et al., 2010 \\
\hline Allium cepa & Allyl sulfide & Chauhan et al., 2010 \\
\hline Aloe vera & $\begin{array}{l}\text { Aloin, aloe-emodin, } \\
\text { pseudoprototinosaponin Alll, } \\
\text { prototinosaponin Alll }\end{array}$ & $\begin{array}{l}\text { Patel et al., 2012; } \\
\text { Eddouks et al., } 2014\end{array}$ \\
\hline Arctium lappa & $\begin{array}{l}\text { Sitosterol-beta-D- } \\
\text { glucopyranoside }\end{array}$ & Chan et al., 2011 \\
\hline Cannabis sativa & Cannabinoids, cannabinol & $\begin{array}{l}\text { Chauhan et al., 2010; } \\
\text { Di Marzo et al., } 2011\end{array}$ \\
\hline Lycium barbarum & Polysaccharide & Zhao et al., 2005 \\
\hline Morus alba & Moran A & Chauhan et al., 2010 \\
\hline Olea europaea & Triterpenoids & Eddouks et al., 2014 \\
\hline Oryza sativa & Glycan & Chauhan et al., 2010 \\
\hline Psidium guajava & $\begin{array}{l}\text { Vescalagin, strictinin, } \\
\text { isostrictinin, pedunculagin }\end{array}$ & $\begin{array}{l}\text { Patel et al., 2012; } \\
\text { Eddouks et al., } 2014\end{array}$ \\
\hline Punica granatum & Gallic acid, ellagic acid & Farzaei et al., 2017 \\
\hline Stevia rebaudiana & Stevioside & Patel et al., 2012 \\
\hline Ziziphus spina-christi & Christinin-A & Patel et al., 2012 \\
\hline
\end{tabular}

wine, Japanese knotweed, peanuts, and roots of rhubarb (Kim et al., 2016), and it has two isomeric forms (Ali et al., 2010). Several studies have reported blood-glucose-lowering effects of resveratrol in animal models (Jiang et al., 2013; Szkudelski and Szkudelska, 2015). Several mechanisms of the antidiabetic action of resveratrol have been reported: improvement of insulin sensitivity; enhancement of GLUT4 translocation; reduction in oxidative stress, regulation of carbohydrate-metabolizing enzymes; activation of sirtuin 1 (SIRT1) and AMPK; and reduction in the expression of adipogenic genes (Bagul and Banerjee, 2015; Bitterman and Chung, 2015). The deacetylase activity of SIRT1 is believed to deacetylate and suppress Foxo1induced transactivation of pyruvate dehydrogenase lipoamide kinase 4 (PDK4), a negative regulator of the glycolytic enzyme pyruvate dehydrogenase (Sin et al., 2015).

Although they have been limited to date, clinical studies combined with data from in vitro and animal studies have indicated the potential antidiabetic effects of resveratrol, as well as its effects on related metabolic disorders, although further studies are warranted specifically regarding its optimal doses (Wang et al., 2014).

\section{Flavonoids}

Flavonoids are secondary metabolites of plants and fungi that have a 15-carbon skeleton (Figure 3) that contains two phenyl rings and heterocyclic ring, and they are primarily known as the pigments responsible for producing the many colors of flowers, fruit, and leaves (Kawser Hossain et al., 2016). Several clinical and experimental studies have suggested that flavonoids have positive effects in the treatment, prevention, and alleviation of various diseases (Havsteen, 2002; Jayaprakasam et al., 2006; Lee et al., 2007). The proposed mechanisms of action of flavonoids include antioxidant actions, central nervous system effects, alterations to gut transport, fatty-acid sequestration and processing, PPAR activation, and increased insulin sensitivity (Prasain et al., 2010).

The anthocyanins are flavonoids that are of great nutritional interest as they are one of the major classes of the widely consumed dietary polyphenols in fruit and vegetables (Guo and Ling, 2015). They are especially abundant in dark-colored fruit, such as berries (Pojer et al., 2013; Tsuda, 2016). Over the

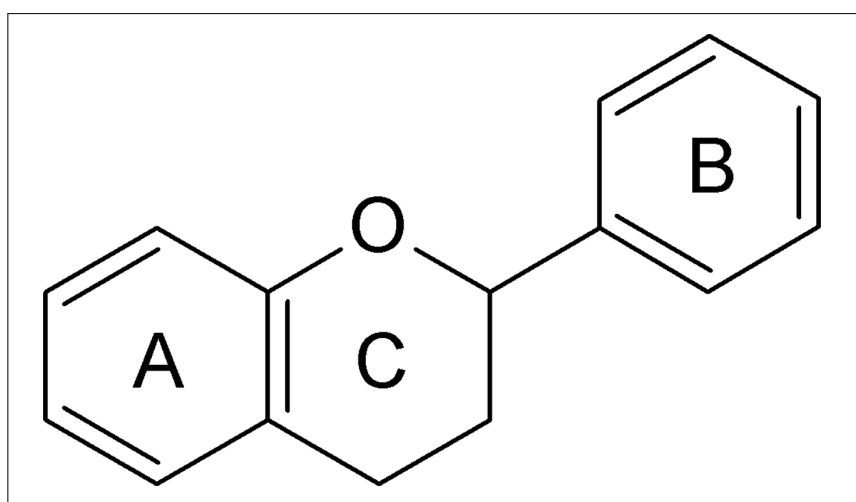

FIGURE 3 | General structure of the 15-carbon skeleton of flavonoids, which consists of two phenyl rings $(A, B)$ and a heterocyclic ring $(C)$. 


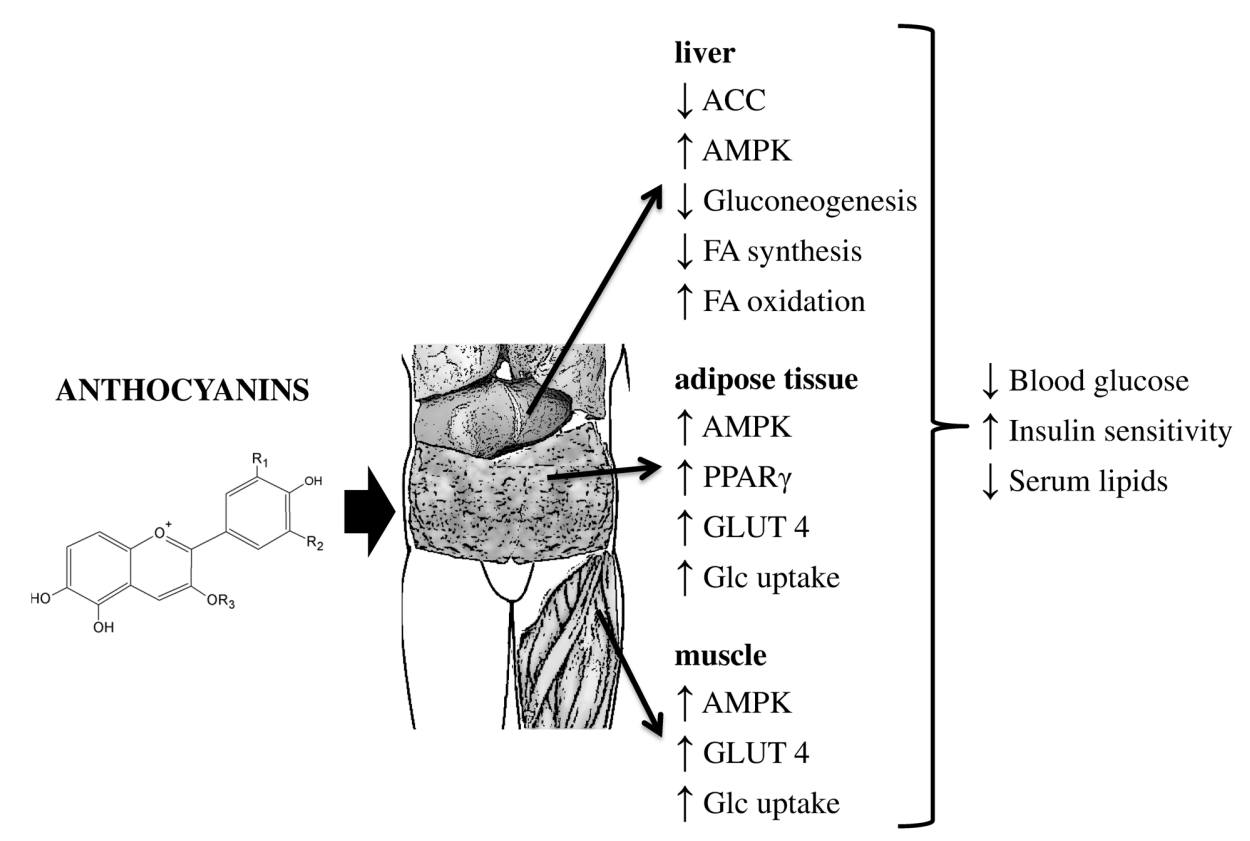

FIGURE 4 | Proposed biological mechanisms underlying the actions of anthocyanins on hyperglycemia and insulin sensitivity. ACC, acetyl-CoA carboxylase; FA, fatty acid; Glc, glucose; GLUT4, glucose transporter 4; PEPCK, phosphoenolpyruvate carboxykinase.

years, the antidiabetic potential of anthocyanin-rich foods has been well documented (Guo and Ling, 2015). A randomized, double-blinded, placebo-controlled clinical study reported by Stull et al. (2010) showed that a daily dietary supplement with bioactives from whole blueberries promoted improved insulin sensitivity in obese, non-diabetic, and insulin-resistant participants. Several studies have been conducted to investigate the impact of the consumption of purified anthocyanins on the development and progression of type 2 diabetes mellitus (Figure 4). These have shown improvements to whole-body insulin sensitivity and significant reduction of fasting blood glucose (Stull et al., 2010), as well as increased serum adiponectin concentrations (Liu et al., 2014). It has been proposed that cyanidin 3-glucoside and its metabolite protocatechuic acid have insulin-like activities through regulation of internalization of glucose via the $\operatorname{PPAR} \gamma$ signaling pathway. The increased $\operatorname{PPAR} \gamma$ activity caused by cyanidin 3-glucoside resulted in upregulation of Glut4 and translocation of GLUT4 to the membrane, as well as enhanced adiponectin secretion in human omental adipocytes (Scazzocchio et al., 2011). Numerous studies have suggested that anthocyanins target AMPK in skeletal muscle and liver, which results in increased glucose uptake and inhibition of gluconeogenesis (Kurimoto et al., 2013). Simultaneously, acetylCoA carboxylase is inactivated and PPAR $\alpha$, acyl-CoA oxidase, and carnitine palmitoyltransferase-1A are upregulated in the liver, which leads to a reduction of the lipid content and enhanced insulin sensitivity (Tsuda, 2016).

One of the limitations of anthocyanins compared to the other flavonoids is their relatively low bioavailability that varies depending on the food matrix, and on other antioxidants and macronutrients in the foods consumed, which consequently affect the absorption and antioxidant potential of anthocyanins (Yang et al., 2011). Celli et al. (2016) proposed a strategy to overcome the limitations in anthocyanin delivery, using gastro-retentive systems that can promote sustained release of anthocyanins. The different structures and the heterogeneity of anthocyanins in berries and their health-promoting effects in synergy with other compounds warrant further studies to fully elucidate and understand the effects of anthocyanins in diabetes and on health in general (Pojer et al., 2013). The majority of epidemiological studies have associated dietary polyphenols with lower risk of type 2 diabetes mellitus; however, these data have been inconsistent. Further well-designed studies are necessary before any specific health claims can be made.

Kaempferol, a dietary flavonol abundant in Ginkgo biloba L., grapefruit, broccoli, kale, tea, and many other edible plants. It was found to have anti-oxidant and anti-inflammatory effects in various disease models, including those for diabetes (Calderón-Montaño et al., 2011). Several mechanisms of its anti-diabetic action were reported. Kaempferol inhibits NF- $\kappa B$ pathway activation, thus inhibits hepatic inflammation, which is contributing to the improvement of insulin signaling defect in diabetes (Luo et al., 2015). Kaempferol was found to have protective effect on pancreatic $\beta$-cell. Its protective action is associated with improved cAMP signaling, inhibited cellular apoptosis (Zhang and Liu, 2011). Oral administration of kaempferol decreased fasting blood glucose and improved insulin resistance (Vinayagam and $\mathrm{Xu}, 2015)$. Other flavonoids with reported antidiabetic activity are naringin and naringenin, that are mainly found in various citrus fruits such as oranges and grapefruits (Alam et al., 2014). Several anti-diabetic mechanisms of naringenin were reported. In addition to its antioxidative 
potential and its inhibition of intestinal $\alpha$-glucosidase it also exhibits insulin mimetic effect to decrease polyprotein B secretion (Priscilla et al., 2014; Vinayagam and Xu, 2015; Roy et al., 2016). Naringin effects expression of hepatic genes involved in gluconeogenesis and lipid metabolism and thus prevents the development of metabolic syndrome by activating AMPK (Pu et al., 2012). One of the most widely used and widely distributed flavonols in human nutrition with reported antidiabetic and anti-inflammatory activity is quercetin (Vinayagam and $\mathrm{Xu}, 2015$; Li et al., 2016). Several mechanisms of its action include inhibition of intestinal glucose absorption by inhibition of GLUT2 (Kwon et al., 2007), decrease of lipid peroxidation (Coskun et al., 2005), inhibition of $\alpha$-amylase and $\alpha$-glucosidase (Meng et al., 2016). With the rapid increase of diabetes incidence, a need for effective phytochemicals with anti-diabetic activity rises. Given the increasing evidence of anti-diabetic activity of flavonoids, it is plausible that consumption of flavonoid-rich foods can reduce the risk of diabetes and that flavonoids can be the potential drugs of choice in management of diabetes mellitus.

\section{CONCLUSION}

Many over-the-counter dietary supplements that still have insufficient medical information and supporting scientific evidence are used in the treatment of patients with diabetes and related metabolic disorders. In majority of the herbal products and secondary metabolites used in treating diabetes, the mechanisms of action involve regulation of insulin signaling pathways, translocation of GLUT-4 receptor and/or activation the PPAR $\gamma$ as well as anti-inflammatory and immunomodulatory action. Although numerous in vitro and in vivo studies, and a number of clinical studies, have reported beneficial effects of various extracts and preparations from plants, the data remain conflicting. The knowledge in this field is still limited and further studies into identifying active ingredients of

\section{REFERENCES}

Aggarwal, S., Shailendra, G., Ribnicky, D. M., Burk, D., Karki, N., and Qingxia Wang, M. S. (2015). An extract of Artemisia dracunculus L. stimulates insulin secretion from $\beta$ cells, activates AMPK and suppresses inflammation. J. Ethnopharmacol. 170, 98-105. doi: 10.1016/j.jep.2015.05.003

Ahameethunisa, A. R., and Hopper, W. (2010). Antibacterial activity of Artemisia nilagirica leaf extracts against clinical and phytopathogenic bacteria. BMC Complement. Altern. Med. 10:6. doi: 10.1186/1472-6882-10-6

Akilen, R., Tsiami, A., Devendra, D., and Robinson, N. (2012). Cinnamon in glycaemic control: systematic review and meta analysis. Clin. Nutr. 31, 609-615. doi: 10.1016/j.clnu.2012.04.003

Alam, M. A., Subhan, N., Rahman, M. M., Uddin, S. J., Reza, H. M., and Sarker, S. D. (2014). Effect of citrus flavonoids, naringin and naringenin, on metabolic syndrome and their mechanisms of action. Adv. Nutr. 5, 404-417. doi: 10.3945/ an. 113.005603

Ali, B. H., Blunden, G., Tanira, M. O., and Nemmar, A. (2008). Some phytochemical, pharmacological and toxicological properties of ginger (Zingiber officinale Roscoe): a review of recent research. Food Chem. Toxicol. 46, 409-420. doi: 10.1016/j.fct.2007.09.085

Ali, K., Maltese, F., Choi, Y. H., and Verpoorte, R. (2010). Metabolic constituents of grapevine and grape-derived products. Phytochem. Rev. 9, 357-378. doi: $10.1007 /$ s11101-009-9158-0 several botanicals and their extracts with reported antidiabetic activity, as well as unveiling their mechanism of action, are needed. Since plants and their extracts constitute numerous active ingredients with unknown effect, caution is needed when interpreting and generalizing antidiabetic properties of such preparations. Synergistic effect of different phyto-derived constituents must also be considered. We must also take into consideration that many phytochemicals taken orally undergo considerable loss of bioactivity. Several novel delivery systems, based on natural materials, are already being developed to counter this problem and increase bioavailability of phytoderived antidiabetic compounds. More studies are warranted to validate their efficacy and safety, and large, well-designed, randomized, double-blind, placebo-controlled, clinical studies need to be carried out before their use can be recommended for treatment and/or prevention of diabetes. As diabetes incidence increases, a need for effective phytochemicals with anti-diabetic activity increases and growing evidence of anti-diabetic activity of several plants or their constituents provides a great pool of potential effective and safe drug for prevention and management of diabetes.

\section{AUTHOR CONTRIBUTIONS}

NPU contributed to idea, writing, editing, and financial support. AO performed writing.

\section{FUNDING}

This study was founded by H2020 - WIDESPREAD-2014-1 TEAMING project ARTEMIDA (Advanced Regional Translation of Excellence into Medical Innovations for Delayed Aging) and by the Slovenian Research Agency (research core funding No. P4-0121).

Al-Qattan, K. K., Mansour, M. H., Thomson, M., and Ali, M. (2016). Garlic decreases liver and kidney receptor for advanced glycation end products expression in experimental diabetes. Pathophysiology 23, 135-145. doi: 10.1016/ j.pathophys.2016.02.003

Anderson, J. W., Allgood, L. D., Turner, J., Oeltgen, P. R., and Daggy, B. P. (1999). Effects of psyllium on glucose and serum lipid responses in men with type 2 diabetes and hypercholesterolemia. Am. J. Clin. Nutr. 70, 466-473.

Andrade-Cetto, A., and Wiedenfeld, H. (2011). Anti-hyperglycemic effect of Opuntia streptacantha Lem. J. Ethnopharmacol. 133, 940-943. doi: 10.1016/j. jep.2010.11.022

Arablou, T., Aryaeian, N., Valizadeh, M., Sharifi, F., Hosseini, A., and Djalali, M. (2014). The effect of ginger consumption on glycemic status, lipid profile and some inflammatory markers in patients with type 2 diabetes mellitus. Int. J. Food Sci. Nutr. 65, 515-520. doi: 10.3109/09637486.2014. 880671

Aronson, D. (2008). Hyperglycemia and the pathobiology of diabetic complications. Adv. Cardiol. 45, 1-16. doi: 10.1159/0000115118

Ashraf, R., Khan, R. A., and Ashraf, I. (2011). Garlic (Allium sativum) supplementation with standard antidiabetic agent provides better diabetic control in type 2 diabetes patients. Pak. J. Pharm. Sci. 24, 565-570.

Atkin, M., Laight, D., and Cummings, M. H. (2016). The effects of garlic extract upon endothelial function, vascular inflammation, oxidative stress and insulin resistance in adults with type 2 diabetes at high cardiovascular risk. A pilot 
double blind randomized placebo controlled trial. J. Diabetes Complications 30, 723-727. doi: 10.1016/j.jdiacomp.2016.01.003

Auwerx, J., Schoonjans, K., Fruchart, J.-C., and Staels, B. (1996). Transcriptional control of triglyceride metabolism: fibrates and fatty acids change the expression of the LPL and apo C-III genes by activating the nuclear receptor PPAR. Atherosclerosis 124, 29-37. doi: 10.1016/0021-9150(96)05854-6

Bagul, P. K., and Banerjee, S. K. (2015). Application of resveratrol in diabetes: rationale, strategies and challenges. Curr. Mol. Med. 15, 312-330. doi: 10.2174/ 1566524015666150505155702

Bahadoran, Z., Mirmiran, P., and Azizi, F. (2013). Dietary polyphenols as potential nutraceuticals in management of diabetes: a review. J. Diabetes Metab. Disord. 12, 1-9. doi: 10.1186/2251-6581-12-43

Baldwa, V. S., Bhandari, C. M., Pangaria, A., and Goyal, R. K. (1977). Clinical trial in patients with diabetes mellitus of an insulin-like compound obtained from plant source. Ups. J. Med. Sci. 82, 39-41. doi: 10.3109/03009737709179057

Baluchnejadmojarad, T., Kiasalari, Z., Afshin-Majd, S., Ghasemi, Z., and Roghani, M. (2017). S-allyl cysteine ameliorates cognitive deficits in streptozotocin-diabetic rats via suppression of oxidative stress, inflammation, and acetylcholinesterase. Eur. J. Pharmacol. 794, 69-76. doi: 10.1016/j.ejphar. 2016.11.033

Baskaran, K., Kizar Ahamath, B., Radha Shanmugasundaram, K., and Shanmugasundaram, E. R. (1990). Antidiabetic effect of a leaf extract from Gymnema sylvestre in non-insulin-dependent diabetes mellitus patients. J. Ethnopharmacol. 30, 295-300. doi: 10.1016/0378-8741(90)90108-6

Bayan, L., Koulivand, P. H., and Gorji, A. (2014). Garlic: a review of potential therapeutic effects. Avicenna J. Phytomed. 4, 1-14.

Baynes, J. W., and Thorpe, S. R. (1999). Role of oxidative stress in diabetic complications: a new perspective on an old paradigm. Diabetes Metab. Res. Rev. 48, 1-9. doi: $10.2337 /$ diabetes.48.1.1

Becerra-Jiménez, J., and Andrade-Cetto, A. (2012). Effect of Opuntia streptacantha Lem. on alpha-glucosidase activity. J. Ethnopharmacol. 139, 493-496. doi: 10.1016/j.jep.2011.11.039

Bellamy, L., Casas, J.-P., Hingorani, A. D., and Williams, D. (2009). Type 2 diabetes mellitus after gestational diabetes: a systematic review and meta-analysis. Lancet 373, 1773-1779. doi: 10.1016/S0140-6736(09)60731-5

Bitterman, J. L., and Chung, J. H. (2015). Metabolic effects of resveratrol: addressing the controversies. Cell. Mol. Life Sci. 72, 1473-1488. doi: 10.1007/ s00018-014-1808-8

Calderón-Montaño, J. M., Burgos-Morón, E., Pérez-Guerrero, C., and LópezLázaro, M. (2011). A review on the dietary flavonoid kaempferol. Mini Rev. Med. Chem. 11, 298-344. doi: 10.2174/138955711795305335

Campbell, A. P. (2010). Diabetes and dietary supplements. Clin. Diabetes 28, 35-39. doi: $10.2337 /$ diaclin.28.1.35

Cefalu, W. T., Ye, J., and Wang, Z. Q. (2008). Efficacy of dietary supplementation with botanicals on carbohydrate metabolism in humans. Endocr. Metab. Immune Disord. Drug Targets 8, 78-81. doi: 10.2174/187153008784534376

Celli, G. B., Kalt, W., and Brooks, M. S.-L. (2016). Gastroretentive systems - a proposed strategy to modulate anthocyanin release and absorption for the management of diabetes. Drug Deliv. 23, 1892-1901. doi: 10.3109/10717544. 2016.1143058

Ceriello, A. (2000). Oxidative stress and glycemic regulation. Metabolism 49, 27-29. doi: 10.1016/S0026-0495(00)80082-7

Chan, Y.-S., Cheng, L.-N., Wu, J.-H., Chan, E., Kwan, Y.-W., Lee, S. M.Y., et al. (2011). A review of the pharmacological effects of Arctium lappa (burdock). Inflammopharmacology 19, 245-254. doi: 10.1007/s10787-0100062-4

Chaturvedi, P. (2012). Antidiabetic potentials of Momordica charantia: multiple mechanisms behind the effects. J. Med. Food 15, 101-107. doi: 10.1089/jmf. 2010.0258

Chauhan, A., Sharma, P., Srivastava, P., Kumar, N., and Duehe, R. (2010). Plants having potential antidiabetic activity: a review. Der Pharm. Lett. 2, 369-387.

Chehade, J. M., Gladysz, M., and Mooradian, A. D. (2013). Dyslipidemia in type 2 diabetes: prevalence, pathophysiology, and management. Drugs 73, 327-339. doi: 10.1007/s40265-013-0023-5

Chen, L., Sun, P., Wang, T., Chen, K., Jia, Q., Wang, H., et al. (2012). Diverse mechanisms of antidiabetic effects of the different procyanidin oligomer types of two different cinnamon species on $\mathrm{db} / \mathrm{db}$ mice. J. Agric. Food Chem. 60, 9144-9150. doi: $10.1021 / \mathrm{jf3} 3024535$
Cheng, D. M., Kuhn, P., Poulev, A., Rojo, L. E., Lila, M. A., and Raskin, I. (2012). In vivo and in vitro antidiabetic effects of aqueous cinnamon extract and cinnamon polyphenol-enhanced food matrix. Food Chem. 135, 2994-3002. doi: 10.1016/j.foodchem.2012.06.117

Cho, W. C. S., Chung, W.-S., Lee, S. K. W., Leung, A. W. N., Cheng, C. H. K., and Yue, K. K. M. (2006). Ginsenoside Re of Panax ginseng possesses significant antioxidant and antihyperlipidemic efficacies in streptozotocininduced diabetic rats. Eur. J. Pharmacol. 550, 173-179. doi: 10.1016/j.ejphar. 2006.08.056

Christensen, L. P. (2009). Ginsenosides chemistry, biosynthesis, analysis, and potential health effects. Adv. Food Nutr. Res. 55, 1-99. doi: 10.1016/S10434526(08)00401-4

ClinicalTrials.gov (2016). Available at: https://clinicaltrials.gov/ct2/show/ NCT02370121 [accessed May 20, 2017].

Coskun, O., Kanter, M., Korkmaz, A., and Oter, S. (2005). Quercetin, a flavonoid antioxidant, prevents and protects streptozotocin-induced oxidative stress and? $\beta$-cell damage in rat pancreas. Pharmacol. Res. 51, 117-123. doi: 10.1016/j. phrs.2004.06.002

Cota-Sánchez, J. H. (2016). "Chapter 28 - nutritional composition of the prickly pear (Opuntia ficus-indica) fruit," in Nutritional Composition of Fruit Cultivars, eds M. Simmonds and V. R. Preedy (Cambridge, MA: Academic Press), 691-712.

Dey, L., Xie, J. T., Wang, A., Wu, J., Maleckar, S. A., and Yuan, C. S. (2003). Anti-hyperglycemic effects of ginseng: comparison between root and berry. Phytomedicine 10, 600-605. doi: 10.1078/094471103322331908

Di Marzo, V., Piscitelli, F., and Mechoulam, R. (2011). Cannabinoids and endocannabinoids in metabolic disorders with focus on diabetes. Handb. Exp. Pharmacol. 203, 75-104. doi: 10.1007/978-3-642-17214-4_4

Donath, M. Y., and Shoelson, S. E. (2011). Type 2 diabetes as an inflammatory disease. Nat. Rev. Immunol. 11, 98-107. doi: 10.1038/nri2925

Eddouks, M., Bidi, A., El Bouhali, B., Hajji, L., and Zeggwagh, N. A. (2014). Antidiabetic plants improving insulin sensitivity. J. Pharm. Pharmacol. 66, 1197-1214. doi: 10.1111/jphp.12243

Efird, J. T., Choi, Y. M., Davies, S. W., Mehra, S., Anderson, E. J., and Katunga, L. A. (2014). Potential for improved glycemic control with dietary Momordica charantia in patients with insulin resistance and pre-diabetes. Int. J. Environ. Res. Public Health 11, 2328-2345. doi: 10.3390/ijerph110202328

EFSA (2015a). Botanicals | European Food Safety Authority. Available at: http:// www.efsa.europa.eu/en/topics/topic/botanicals [accessed November 16, 2015].

EFSA (2015b). Food Supplements | European Food Safety Authority. Food Suppl. Available at: http://www.efsa.europa.eu/en/topics/topic/supplements [accessed November 16, 2015].

Eidi, A., Eidi, M., and Esmaeili, E. (2006). Antidiabetic effect of garlic (Allium sativum L.) in normal and streptozotocin-induced diabetic rats. Phytomedicine 13, 624-629. doi: 10.1016/j.phymed.2005.09.010

Eidi, A., Oryan, S., Zaringhalam, J., and Rad, M. (2016). Antinociceptive and anti-inflammatory effects of the aerial parts of Artemisia dracunculus in mice. Pharm. Biol. 54, 549-554. doi: 10.3109/13880209.2015.1056312

Evans, J. L., and Bahng, M. (2014). Non-pharmaceutical Intervention Options for type 2 Diabetes: Diets and Dietary Supplements (Botanicals, Antioxidants, and Minerals), Eds De Groot LJ, Chrousos G, Dungan K, Feingold KR, Grossman A, Hershman JM et al. South Dartmouth MA: MDText.com, Inc.

Facchinetti, F., Dante, G., Petrella, E., and Neri, I. (2014). Dietary interventions, lifestyle changes, and dietary supplements in preventing gestational diabetes mellitus: a literature review. Obstet. Gynecol. Surv. 69, 669-680. doi: 10.1097/ OGX.0000000000000121

Farzaei, F., Morovati, M. R., Farjadmand, F., and Farzaei, M. H. (2017). A mechanistic review on medicinal plants used for diabetes mellitus in traditional persian medicine. J. Evid. Based Complement. Altern. Med. doi: 10.1177/2156587216686461 [Epub ahead of print].

Frati, A. C., Gordillo, B. E., Altamirano, P., Ariza, C. R., Cortés-Franco, R., and Chavez-Negrete, A. (1990). Acute hypoglycemic effect of Opuntia streptacantha Lemaire in NIDDM. Diabetes Care 13, 455-456. doi: 10.2337/diacare.13.4.455

Fuller, S., and Stephens, J. M. (2015). Diosgenin, 4-hydroxyisoleucine, and fiber from fenugreek: mechanisms of actions and potential effects on metabolic syndrome. Adv. Nutr. 6, 189-197. doi: 10.3945/an.114.007807

Gaddam, A., Galla, C., Thummisetti, S., Marikanty, R. K., Palanisamy, U. D., and Rao, P. V. (2015). Role of Fenugreek in the prevention of type 2 diabetes mellitus 
in prediabetes. J. Diabetes Metab. Disord. 14, 1-10. doi: 10.1186/s40200-0150208-4

Gonçalves, S., and Romano, A. (2016). The medicinal potential of plants from the genus Plantago (Plantaginaceae). Ind. Crops Prod. 83, 213-226. doi: 10.1016/j. indcrop.2015.12.038

González-Stuart, A. E. (2013). Bioactive Food as Dietary Interventions for Diabetes. San Diego, CA: Academic Press, 658.

Govorko, D., Logendra, S., Wang, Y., Esposito, D., Komarnytsky, S., Ribnicky, D., et al. (2007). Polyphenolic compounds from Artemisia dracunculus L. inhibit PEPCK gene expression and gluconeogenesis in an H4IIE hepatoma cell line. Am. J. Physiol. Endocrinol. Metab. 293, 1503-1510. doi: 10.1152/ajpendo.00420. 2007

Grover, J. K., and Yadav, S. P. (2004). Pharmacological actions and potential uses of Momordica charantia: a review. J. Ethnopharmacol. 93, 123-132. doi: 10.1016/j. jep.2004.03.035

Gui, Q., Xu, Z., Xu, K., and Yang, Y. (2016). The efficacy of ginseng-related therapies in type 2 diabetes mellitus. Medicine 95:e2584. doi: 10.1097/MD. 0000000000002584

Guo, H., and Ling, W. (2015). The update of anthocyanins on obesity and type 2 diabetes: experimental evidence and clinical perspectives. Rev. Endocr. Metab. Disord. 16, 1-13. doi: 10.1007/s11154-014-9302-z

Hanhineva, K., Törrönen, R., Bondia-Pons, I., Pekkinen, J., Kolehmainen, M., Mykkänen, H., et al. (2010). Impact of dietary polyphenols on carbohydrate metabolism. Int. J. Mol. Sci. 11, 1365-1402. doi: 10.3390/ijms11041365

Hannan, J. M. A., Ali, L., Rokeya, B., Khaleque, J., Akhter, M., Flatt, P. R., et al. (2007). Soluble dietary fibre fraction of Trigonella foenum-graecum (fenugreek) seed improves glucose homeostasis in animal models of type 1 and type 2 diabetes by delaying carbohydrate digestion and absorption, and enhancing insulin action. Br. J. Nutr. 97, 514-521. doi: 10.1017/S00071145076 57869

Havsteen, B. H. (2002). The biochemistry and medical significance of the flavonoids. Pharmacol. Ther. 96, 67-202. doi: 10.1016/S0163-7258(02)00298-X

Ho, J.-N., Watson, R. R., and Lee, J. (2013). Bioactive Food as Dietary Interventions for Diabetes. San Diego, CA: Academic Press, 658.

Hosni, A. A., Abdel-Moneim, A. A., Abdel-Reheim, E. S., Mohamed, S. M., and Helmy, H. (2017). Cinnamaldehyde potentially attenuates gestational hyperglycemia in rats through modulation of $\operatorname{PPAR} \gamma$, proinflammatory cytokines and oxidative stress. Biomed. Pharmacother. 88, 52-60. doi: 10.1016/ j.biopha.2017.01.054

Hossain, M. Z., Shibib, B. A., and Rahman, R. (1992). Hypoglycemic effects of Coccinia indica: inhibition of key gluconeogenic enzyme, glucose-6phosphatase. Indian J. Exp. Biol. 30, 418-420.

Ibañez-Camacho, R., Meckes-Lozoya, M., and Mellado-Campos, V. (1983). The hypoglucemic effect of Opuntia streptacantha studied in different animal experimental models. J. Ethnopharmacol. 7, 175-181. doi: 10.1016/03788741(83)90019-3

Iciek, M., Kwiecieñ, I., and Włodek, L. (2009). Biological properties of garlic and garlic-derived organosulfur compounds. Environ. Mol. Mutagen. 50, 247-265. doi: $10.1002 / \mathrm{em} .20474$

Imoto, T., Miyasaka, A., Ishima, R., and Akasaka, K. (1991). A novel peptide isolated from the leaves of Gymnema sylvestre-I. Characterization and its suppressive effect on the neural responses to sweet taste stimuli in the rat. Comp. Biochem. Physiol. Part A Physiol. 100, 309-314. doi: 10.1016/0300-9629(91) 90475-R

International Diabetes Federation (2013). Diabetes Atlas, 6th Edn. Available at: www.idf.org/diabetesatlas [accessed November 16, 2015].

Islam, M. S., and Choi, H. (2008). Comparative effects of dietary ginger (Zingiber officinale) and garlic (Allium sativum) investigated in a type 2 diabetes model of rats. J. Med. Food 11, 152-159. doi: 10.1089/jmf.2007.634

Itariu, B. K., and Stulnig, T. M. (2014). Autoimmune aspects of type 2 diabetes mellitus - a mini-review. Gerontology 60, 189-196. doi: 10.1159/000356747

Jayaprakasam, B., Olson, L. K., Schutzki, R. E., Tai, M.-H., and Nair, M. G. (2006). Amelioration of obesity and glucose intolerance in high-fat-fed C57BL/6 mice by anthocyanins and ursolic acid in Cornelian cherry (Cornus mas). J. Agric. Food Chem. 54, 243-248. doi: 10.1021/jf0520342

Jetté, L., Harvey, L., Eugeni, K., and Levens, N. (2009). 4-Hydroxyisoleucine: a plant-derived treatment for metabolic syndrome. Curr. Opin. Investig. Drugs $10,353-358$
Jiang, B., Guo, L., Li, B.-Y., Zhen, J.-H., Song, J., Peng, T., et al. (2013). Resveratrol attenuates early diabetic nephropathy by down-regulating glutathione S-Transferases $\mathrm{Mu}$ in diabetic rats. J. Med. Food 16, 481-486. doi: 10.1089/jmf.2012.2686

Jiang, B., Ji, M., Liu, W., Chen, L., Cai, Z., Zhao, Y., et al. (2016). Antidiabetic activities of a cucurbitane-type triterpenoid compound from Momordica charantia in alloxan-induced diabetic mice. Mol. Med. Rep. 14, 4865-4872. doi: 10.3892/mmr.2016.5800

Jolad, S. D., Lantz, R. C., Solyom, A. M., Chen, G. J., Bates, R. B., and Timmermann, B. N. (2004). Fresh organically grown ginger (Zingiber officinale): composition and effects on LPS-induced PGE2 production. Phytochemistry 65, 1937-1954. doi: 10.1016/j.phytochem.2004.06.008

Joseph, B., and Jini, D. (2013). Antidiabetic effects of Momordica charantia (bitter melon) and its medicinal potency. Asian Pac. J. Trop. Dis. 3, 93-102. doi: 10.1016/S2222-1808(13)60052-3

Kalailingam, P., Kannaian, B., Tamilmani, E., and Kaliaperumal, R. (2014). Efficacy of natural diosgenin on cardiovascular risk, insulin secretion, and beta cells in streptozotocin (STZ)-induced diabetic rats. Phytomedicine 21, 1154-1161. doi: 10.1016/j.phymed.2014.04.005

Kamble, B., Gupta, A., Moothedath, I., Khatal, L., Janrao, S., Jadhav, A., et al. (2016). Effects of Gymnema sylvestre extract on the pharmacokinetics and pharmacodynamics of glimepiride in streptozotocin induced diabetic rats. Chem. Biol. Interact. 245, 30-38. doi: 10.1016/j.cbi.2015 12.008

Kamble, S., Kamlakar, P., Vaidya, S., and Bambole, V. (1998). Influence of Coccinia indica on certain enzymes in glycolytic and lipolytic pathway in human diabetes. Indian J. Med. Sci. 52, 143-146.

Kaprio, J., Tuomilehto, J., Koskenvuo, M., Romanov, K., Reunanen, A., Eriksson, J., et al. (1992). Concordance for type 1 (insulin-dependent) and type 2 (noninsulin-dependent) diabetes mellitus in a population-based cohort of twins in Finland. Diabetologia 35, 1060-1067. doi: 10.1007/BF02221682

Kawser Hossain, M., Abdal Dayem, A., Han, J., Yin, Y., Kim, K., Kumar Saha, S., et al. (2016). Molecular mechanisms of the anti-obesity and anti-diabetic properties of flavonoids. Int. J. Mol. Sci. 17, 1-32. doi: 10.3390/ijms170 40569

Khanna, P., Jain, S. C., Panagariya, A., and Dixit, V. P. (1981). Hypoglycemic activity of polypeptide-p from a plant source. J. Nat. Prod. 44, 648-655. doi: $10.1021 / \mathrm{np} 50018 \mathrm{a} 002$

Kheterpal, I., Scherp, P., Kelley, L., Wang, Z., Johnson, W., Ribnicky, D., et al. (2014). Bioactives from Artemisia dracunculus L. enhance insulin sensitivity via modulation of skeletal muscle protein phosphorylation. Nutrition 30, 43-51. doi: 10.1016/j.nut.2014.05.001

Khramov, V. A., Spasov, A. A., and Samokhina, M. P. (2008). Chemical composition of dry extracts of Gymnema sylvestre leaves. Pharm. Chem. J. 42, 29-31. doi: 10.1007/s11094-008-0051-8

Kim, Y., Keogh, J. B., and Clifton, P. M. (2016). Polyphenols and glycemic control. Nutrients 8, 17. doi: 10.3390/nu8010017

King, G. L., and Loeken, M. R. (2004). Hyperglycemia-induced oxidative stress in diabetic complications. Histochem. Cell Biol. 122, 333-338. doi: 10.1007/s00418004-0678-9

Kumar, V., Bhandari, U., Tripathi, C. D., and Khanna, G. (2014). Protective effect of Gymnema sylvestre ethanol extract on high fat diet-induced obese diabetic wistar rats. Indian J. Pharm. Sci. 76, 315-322.

Kurimoto, Y., Shibayama, Y., Inoue, S., Soga, M., Takikawa, M., Ito, C., et al. (2013). Black soybean seed coat extract ameliorates hyperglycemia and insulin sensitivity via the activation of AMP-activated protein kinase in diabetic mice. J. Agric. Food Chem. 61, 5558-5564. doi: 10.1021/jf401190y

Kuriyan, R., Rajendran, R., Bantwal, G., and Kurpad, A. V. (2008). Effect of supplementation of Coccinia cordifolia extract on newly detected diabetic patients. Diabetes Care 31, 216-220. doi: 10.2337/dc07-1591

Kwon, O., Eck, P., Chen, S., Corpe, C. P., Lee, J.-H., Kruhlak, M., et al. (2007). Inhibition of the intestinal glucose transporter GLUT2 by flavonoids. FASEB J. 21, 366-377. doi: 10.1096/fj.06-6620com

Leach, M. J. (2007). Gymnema sylvestre for diabetes mellitus: a systematic review. J. Altern. Complement. Med. 13, 977-983. doi: 10.1089/acm.2006.6387

Lee, E.-R., Kang, G.-H., and Cho, S.-G. (2007). Effect of flavonoids on human health: old subjects but new challenges. Recent Pat. Biotechnol. 1, 139-150. doi: $10.2174 / 187220807780809445$ 
Leem, K.-H., Kim, M.-G., Hahm, Y.-T., and Kim, H. (2016). Hypoglycemic effect of Opuntia ficus-indica var. saboten is due to enhanced peripheral glucose uptake through activation of AMPK/p38 MAPK pathway. Nutrients 8,800 .

Li, Y., Yao, J., Han, C., Yang, J., Chaudhry, M. T., Wang, S., et al. (2016). Quercetin, inflammation and immunity. Nutrients 8, 167. doi: 10.3390/nu8030167

Li, Y., Zheng, M., Zhai, X., Huang, Y., Khalid, A., Malik, A., et al. (2015). Effect ofGymnema sylvestre, citrullus colocynthis and Artemisia absinthium on blood glucose and lipid profile in diabetic human. Acta Pol. Pharm. 72, 981-985.

Liu, C.-T., Wong, P.-L., Lii, C.-K., Hse, H., and Sheen, L.-Y. (2006). Antidiabetic effect of garlic oil but not diallyl disulfide in rats with streptozotocin-induced diabetes. Food Chem. Toxicol. 44, 1377-1384. doi: 10.1016/j.fct.2005.07.013

Liu, Y., Li, D., Zhang, Y., Sun, R., and Xia, M. (2014). Anthocyanin increases adiponectin secretion and protects against diabetes-related endothelial dysfunction. Am. J. Physiol. Endocrinol. Metab. 306, 975-988. doi: 10.1152/ ajpendo.00699.2013

Lopes-Lutz, D., Alviano, D. S., Alviano, C. S., and Kolodziejczyk, P. P. (2008). Screening of chemical composition, antimicrobial and antioxidant activities of Artemisia essential oils. Phytochemistry 69, 1732-1738. doi: 10.1016/j. phytochem.2008.02.014

López-Romero, P., Pichardo-Ontiveros, E., Avila-Nava, A., Vázquez-Manjarrez, N., Tovar, A. R., Pedraza-Chaverri, J., et al. (2014). The effect of nopal (Opuntia ficus indica) on postprandial blood glucose, incretins, and antioxidant activity in Mexican patients with type 2 diabetes after consumption of two different composition breakfasts. J. Acad. Nutr. Diet. 114, 1811-1818. doi: 10.1016/j.jand. 2014.06.352

Lu, Z., Jia, Q., Wang, R., Wu, X., Wu, Y., Huang, C., et al. (2011). Hypoglycemic activities of A- and B-type procyanidin oligomer-rich extracts from different Cinnamon barks. Phytomedicine 18, 298-302. doi: 10.1016/j.phymed.2010.08.008

Luo, C., Yang, H., Tang, C., Yao, G., Kong, L., He, H., et al. (2015). Kaempferol alleviates insulin resistance via hepatic IKK/NF-KB signal in type 2 diabetic rats. Int. Immunopharmacol. 28, 744-750. doi: 10.1016/j.intimp.2015.07.018

Mamun-or-Rashid, A., Shamim Hossain, M., Hassan, N., Kumar Dash, B., Ashrafuzzaman Sapon, M., and Kumer Sen, M. (2014). A review on medicinal plants with antidiabetic activity. J. Pharmacogn. Phytochem. 149, 149-159.

Manach, C., Scalbert, A., Morand, C., Rémésy, C., and Jiménez, L. (2004). Polyphenols: food sources and bioavailability. Am. J. Clin. Nutr. 79, 727-747.

Maritim, A. C., Sanders, R. A., and Watkins, J. B. (2003). Diabetes, oxidative stress, and antioxidants: a review. J. Biochem. Mol. Toxicol. 17, 24-38. doi: $10.1002 /$ jbt. 10058

Matsuda, A., and Kuzuya, T. (1994). Relationship between obesity and concordance rate for type 2 (non-insulin-dependent) diabetes mellitus among twins. Diabetes Res. Clin. Pract. 26, 137-143. doi: 10.1016/0168-8227(94) 90151-1

Medagama, A. B. (2015). The glycaemic outcomes of Cinnamon, a review of the experimental evidence and clinical trials. Nutr. J. 14, 108. doi: 10.1186/s12937015-0098-9

Méndez-del Villar, M., Puebla-Pérez, A. M., Sánchez-Peña, M. J., González-Ortiz, L. J., Martínez-Abundis, E., and González-Ortiz, M. (2016). Effect of Artemisia dracunculus administration on glycemic control, insulin sensitivity, and insulin secretion in patients with impaired glucose tolerance. J. Med. Food 19, 481-485. doi: 10.1089/jmf.2016.0005

Meng, Y., Su, A., Yuan, S., Zhao, H., Tan, S., Hu, C., et al. (2016). Evaluation of total flavonoids, myricetin, and quercetin from Hovenia dulcis Thunb. as inhibitors of $\alpha$-amylase and $\alpha$-glucosidase. Plant Foods Hum. Nutr. 71, 444-449. doi: 10.1007/s11130-016-0581-2

Mirunalini, S., Krishnaveni, M., Ambily, V., and Professor, A. (2011). Effects of raw garlic (Allium Sativum) on hyperglycemia in patients with type 2 diabetes mellitus. Pharmacologyonline 2, 968-974.

Moreno, L. A., Tresaco, B., Bueno, G., Fleta, J., Rodríguez, G., Garagorri, J. M., et al. (2003). Psyllium fibre and the metabolic control of obese children and adolescents. J. Physiol. Biochem. 59, 235-242. doi: 10.1007/BF03179920

Munasinghe, M. A. A. K., Abeysena, C., Yaddehige, I. S., Vidanapathirana, T., and Piyumal, K. P. B. (2011). Blood sugar lowering effect of Coccinia grandis (L.) J. Voigt: path for a new drug for diabetes mellitus. Exp. Diabetes Res. 2011, 978762. doi: $10.1155 / 2011 / 978762$
Neelakantan, N., Narayanan, M., de Souza, R. J., and van Dam, R. M. (2014). Effect of fenugreek (Trigonella foenum-graecum L.) intake on glycemia: a meta-analysis of clinical trials. Nutr. J. 13, 7. doi: 10.1186/1475-2891-13-7

Newman, B., Selby, J. V., King, M. C., Slemenda, C., Fabsitz, R., and Friedman, G. D. (1987). Concordance for type 2 (non-insulin-dependent) diabetes mellitus in male twins. Diabetologia 30, 763-768. doi: 10.1007/BF00275741

Obanda, D. N., Ribnicky, D. M., Raskin, I., and Cefalu, W. T. (2014). Bioactives of Artemisia dracunculus L. enhance insulin sensitivity by modulation of ceramide metabolism in rat skeletal muscle cells. Nutrition 30, 59-66. doi: 10.1016/j.nut. 2014.03.006

Obolskiy, D., Pischel, I., Feistel, B., Glotov, N., and Heinrich, M. (2011). Artemisia dracunculus L. (tarragon): a critical review of its traditional use, chemical composition, pharmacology, and safety. J. Agric. Food Chem. 59, 11367-11384. doi: $10.1021 / \mathrm{jf} 202277 \mathrm{w}$

Padiya, R., and Banerjee, S. K. (2013). Garlic as an anti-diabetic agent: recent progress and patent reviews. Recent Pat. Food. Nutr. Agric. 5, 105-127. doi: $10.2174 / 18761429113059990002$

Padiya, R., Khatua, T. N., Bagul, P. K., Kuncha, M., and Banerjee, S. K. (2011). Garlic improves insulin sensitivity and associated metabolic syndromes in fructose fed rats. Nutr. Metab. 8, 53. doi: 10.1186/1743-7075-8-53

Pal, S., and Radavelli-Bagatini, S. (2012). Effects of psyllium on metabolic syndrome risk factors. Obes. Rev. 13, 1034-1047. doi: 10.1111/j.1467-789X.2012.01020.x

Park, E. J., and Pezzuto, J. M. (2002). Botanicals in cancer chemoprevention. Cancer Metastasis Rev. 21, 231-255. doi: 10.1023/A:1021254725842

Park, E.-J., and Pezzuto, J. M. (2015). The pharmacology of resveratrol in animals and humans. Biochim. Biophys. Acta 1852, 1071-1113. doi: 10.1016/j.bbadis. 2015.01.014

Pastors, J. G., Blaisdell, P. W., Balm, T. K., Asplin, C. M., and Pohl, S. L. (1991). Psyllium fiber reduces rise in postprandial glucose and insulin concentrations in patients with non-insulin-dependent diabetes. Am. J. Clin. Nutr. 53, 1431-1435.

Patel, D. K., Prasad, S. K., Kumar, R., and Hemalatha, S. (2012). An overview on antidiabetic medicinal plants having insulin mimetic property. Asian Pac. J. Trop. Biomed. 2, 320-330. doi: 10.1016/S2221-1691(12)60032-X

Petrovska, B. B. (2012). Historical review of medicinal plants' usage. Pharmacogn. Rev. 6, 1-5. doi: 10.4103/0973-7847.95849

Pojer, E., Mattivi, F., Johnson, D., and Stockley, C. S. (2013). the case for anthocyanin consumption to promote human health: a review. Compr. Rev. Food Sci. Food Saf. 12, 483-508. doi: 10.1111/1541-4337.12024

Prabhakar, P. K., and Doble, M. (2011). Mechanism of action of natural products used in the treatment of diabetes mellitus. Chin. J. Integr. Med. 17, 563-574. doi: 10.1007/s11655-011-0810-3

Prasain, J. K., Carlson, S. H., and Wyss, J. M. (2010). Flavonoids and age-related disease: risk, benefits and critical windows. Maturitas 66, 163-171. doi: 10.1016/ j.maturitas.2010.01.010

Priscilla, D. H., Roy, D., Suresh, A., Kumar, V., and Thirumurugan, K. (2014). Naringenin inhibits $\alpha$-glucosidase activity: a promising strategy for the regulation of postprandial hyperglycemia in high fat diet fed streptozotocin induced diabetic rats. Chem. Biol. Interact. 210, 77-85. doi: 10.1016/j.cbi.2013. 12.014

Pu, P., Gao, D.-M., Mohamed, S., Chen, J., Zhang, J., Zhou, X.-Y., et al. (2012). Naringin ameliorates metabolic syndrome by activating AMP-activated protein kinase in mice fed a high-fat diet. Arch. Biochem. Biophys. 518, 61-70. doi: 10.1016/j.abb.2011.11.026

Ribnicky, D. M., Roopchand, D. E., Poulev, A., Kuhn, P., Oren, A., Cefalu, W. T., et al. (2014). Artemisia dracunculus L. polyphenols complexed to soy protein show enhanced bioavailability and hypoglycemic activity in C57BL/6 mice. Nutrition 30, 4-10. doi: 10.1016/j.nut.2014.03.009

Roy, S., Ahmed, F., Banerjee, S., and Saha, U. (2016). Naringenin ameliorates streptozotocin-induced diabetic rat renal impairment by downregulation of TGF- $\beta 1$ and IL- 1 via modulation of oxidative stress correlates with decreased apoptotic events. Pharm. Biol. 54, 1616-1627. doi: 10.3109/13880209.2015. 1110599

Sales, P. M., Souza, P. M., Simeoni, L. A., and Silveira, D. (2012). $\alpha$-Amylase inhibitors: a review of raw material and isolated compounds from plant source. J. Pharm. Pharm. Sci. 15, 141-183. doi: 10.18433/J35S3K

Sathibabu Uddandrao, V. V., Brahmanaidu, P., and Saravanan, G. (2016). Therapeutical Perspectives of S-Allylcysteine: effect on diabetes and other 
disorders in animal models. Cardiovasc. Hematol. Agents Med. Chem. 14, 1-7. doi: 10.2174/1871525714666160418114120

Scazzocchio, B., Varì, R., Filesi, C., D’Archivio, M., Santangelo, C., Giovannini, C., et al. (2011). Cyanidin-3-O- $\beta$-glucoside and protocatechuic acid exert insulinlike effects by upregulating PPAR $\gamma$ activity in human omental adipocytes. Diabetes Metab. Res. Rev. 60, 2234-2244. doi: 10.2337/db10-1461

Shane-McWhorter, L. (2005). Botanical dietary supplements and the treatment of diabetes: what is the evidence? Curr. Diab. Rep. 5, 391-398. doi: 10.1007/ s11892-005-0099-8

Sheng, X., Zhang, Y., Gong, Z., Huang, C., and Zang, Y. Q. (2008). Improved insulin resistance and lipid metabolism by cinnamon extract through activation of peroxisome proliferator-activated receptors. PPAR Res. 2008:581348. doi: $10.1155 / 2008 / 581348$

Shibib, B. A., Khan, L. A., and Rahman, R. (1993). Hypoglycaemic activity of Coccinia indica and Momordica charantia in diabetic rats: depression of the hepatic gluconeogenic enzymes glucose-6-phosphatase and fructose-1,6bisphosphatase and elevation of both liver and red-cell shunt enzyme glucose6-phosphate dehydrogenase. Biochem. J. 292, 267-270. doi: 10.1042/bj2920267

Shidfar, F., Rajab, A., Rahideh, T., Khandouzi, N., Hosseini, S., and Shidfar, S. (2015). The effect of ginger (Zingiber officinale) on glycemic markers in patients with type 2 diabetes. J. Complement. Integr. Med. 12, 165-170. doi: 10.1515/ jcim-2014-0021

Shih, C.-C., Shlau, M.-T., Lin, C.-H., and Wu, J.-B. (2014). Momordica charantia ameliorates insulin resistance and dyslipidemia with altered hepatic glucose production and fatty acid synthesis and AMPK phosphorylation in high-fat-fed mice. Phytother. Res. 28, 363-371. doi: 10.1002/ptr.5003

Shiju, T. M., Rajkumar, R., Rajesh, N. G., and Viswanathan, P. (2013). Aqueous extract of Allium sativum L bulbs offer nephroprotection by attenuating vascular endothelial growth factor and extracellular signal-regulated kinase-1 expression in diabetic rats. Indian J. Exp. Biol. 51, 139-148.

Shishtar, E., Sievenpiper, J. L., Djedovic, V., Cozma, A. I., Ha, V., Jayalath, V. H., et al. (2014). The effect of ginseng (The Genus Panax) on glycemic control: a systematic review and meta-analysis of randomized controlled clinical trials. PLoS ONE 9:e107391. doi: 10.1371/journal.pone.0107391

Shoelson, S. E., Lee, J., and Goldfine, A. B. (2006). Inflammation and insulin resistance. J. Clin. Invest. 116, 1793-1801. doi: 10.1172/JCI29069

Shori, A. B. (2015). Screening of antidiabetic and antioxidant activities of medicinal plants. J. Integr. Med. 13, 297-305. doi: 10.1016/S2095-4964(15)60193-5

Sierra, M., García, J. J., Fernández, N., Diez, M. J., and Calle, A. P. (2002). Therapeutic effects of psyllium in type 2 diabetic patients. Eur. J. Clin. Nutr. 56, 830-842. doi: 10.1038/sj.ejcn.1601398

Sin, T. K., Yung, B. Y., and Siu, P. M. (2015). Modulation of SIRT1-Foxo1 signaling axis by resveratrol: implications in skeletal muscle aging and insulin resistance. Cell. Physiol. Biochem. 35, 541-552. doi: 10.1159/000369718

Son, I. S., Kim, J. H., Sohn, H. Y., Son, K. H., Kim, J.-S., and Kwon, C.-S. (2007). Antioxidative and hypolipidemic effects of diosgenin, a steroidal saponin of yam (Dioscorea spp.), on high-cholesterol fed rats. Biosci. Biotechnol. Biochem. 71, 3063-3071. doi: 10.1271/bbb.70472

Srichamroen, A., Thomson, A. B. R., Field, C. J., and Basu, T. K. (2009). In vitro intestinal glucose uptake is inhibited by galactomannan from Canadian fenugreek seed (Trigonella foenum graecum $\mathrm{L}$ ) in genetically lean and obese rats. Nutr. Res. 29, 49-54. doi: 10.1016/j.nutres.2008.11.002

Stull, A. J., Cash, K. C., Johnson, W. D., Champagne, C. M., and Cefalu, W. T. (2010). Bioactives in blueberries improve insulin sensitivity in obese, insulinresistant men and women. J. Nutr. 140, 1764-1768. doi: 10.3945/jn.110.125336

Szkudelski, T., and Szkudelska, K. (2015). Resveratrol and diabetes: from animal to human studies. Biochim. Biophys. Acta 1852, 1145-1154. doi: 10.1016/j.bbadis. 2014.10.013

Tan, M.-J., Ye, J.-M., Turner, N., Hohnen-Behrens, C., Ke, C.-Q., Tang, C.-P., et al. (2008). Antidiabetic activities of triterpenoids isolated from bitter melon associated with activation of the AMPK pathway. Chem. Biol. 15, 263-273. doi: 10.1016/j.chembiol.2008.01.013

Thakur, V. K., and Thakur, M. K. (2014). Recent trends in hydrogels based on psyllium polysaccharide: a review. J. Clean. Prod. 82, 1-15. doi: 10.1016/j. jclepro.2014.06.066

Thomson, M., Al-Qattan, K. K., Divya, J. S., and Ali, M. (2016). Anti-diabetic and anti-oxidant potential of aged garlic extract (AGE) in streptozotocin-induced diabetic rats. BMC Complement. Altern. Med. 16, 17. doi: 10.1186/s12906-0160992-5

Tiwari, P., Mishra, B. N., and Sangwan, N. S. (2014). Phytochemical and pharmacological properties of Gymnema sylvestre: an important medicinal plant. Biomed. Res. Int. 2014:830285. doi: 10.1155/2014/830285

Trejo-González, A., Gabriel-Ortiz, G., Puebla-Pérez, A. M., Huízar-Contreras, M. D., Munguía-Mazariegos, M. R., Mejía-Arreguín, S., et al. (1996). A purified extract from prickly pear cactus (Opuntia fuliginosa) controls experimentally induced diabetes in rats. J. Ethnopharmacol. 55, 27-33. doi: 10.1016/S03788741(96)01467-5

Tsai, C.-H., Chen, E. C.-F., Tsay, H.-S., and Huang, C. (2012). Wild bitter gourd improves metabolic syndrome: a preliminary dietary supplementation trial. Nutr. J. 11, 4. doi: 10.1186/1475-2891-11-4

Tsuda, T. (2016). Recent progress in anti-obesity and anti-diabetes effect of berries. Antioxidants 5, 13. doi: 10.3390/antiox5020013

Tung, Y.-T., Chua, M.-T., Wang, S.-Y., and Chang, S.-T. (2008). Antiinflammation activities of essential oil and its constituents from indigenous cinnamon (Cinnamomum osmophloeum) twigs. Bioresour. Technol. 99, 3908-3913. doi: 10.1016/j.biortech.2007.07.050

Uemura, T., Hirai, S., Mizoguchi, N., Goto, T., Lee, J.-Y., Taketani, K., et al. (2010). Diosgenin present in fenugreek improves glucose metabolism by promoting adipocyte differentiation and inhibiting inflammation in adipose tissues. Mol. Nutr. Food Res. 54, 1596-1608. doi: 10.1002/mnfr.2009 00609

Vandanmagsar, B., Haynie, K. R., Wicks, S. E., Bermudez, E. M., Mendoza, T. M., Ribnicky, D., et al. (2014). Artemisia dracunculus L. extract ameliorates insulin sensitivity by attenuating inflammatory signalling in human skeletal muscle culture. Diabetes Obes. Metab. 16, 728-738. doi: 10.1111/dom. 12274

Verspohl, E. J., Bauer, K., and Neddermann, E. (2005). Antidiabetic effect of Cinnamomum cassia and Cinnamomum zeylanicum in vivo and in vitro. Phytother. Res. 19, 203-206. doi: 10.1002/ptr.1643

Vinayagam, R., and Xu, B. (2015). Antidiabetic properties of dietary flavonoids: a cellular mechanism review. Nutr. Metab. (Lond). 12, 60. doi: 10.1186/s12986015-0057-7

Vos, T., Flaxman, A. D., Naghavi, M., Lozano, R., Michaud, C., Ezzati, M., et al. (2012). Years lived with disability (YLDs) for 1160 sequelae of 289 diseases and injuries 1990-2010: a systematic analysis for the global burden of disease study 2010. Lancet 380, 2163-2196. doi: 10.1016/S0140-6736(12) 61729-2

Vuksan, V., Sung, M.-K., Sievenpiper, J. L., Stavro, P. M., Jenkins, A. L., Di Buono, M., et al. (2008). Korean red ginseng (Panax ginseng) improves glucose and insulin regulation in well-controlled, type 2 diabetes: results of a randomized, double-blind, placebo-controlled study of efficacy and safety. Nutr. Metab. Cardiovasc. Dis. 18, 46-56. doi: 10.1016/j.numecd.2006. 04.003

Wang, S., Moustaid-Moussa, N., Chen, L., Mo, H., Shastri, A., Su, R., et al. (2014). Novel insights of dietary polyphenols and obesity. J. Nutr. Biochem. 25, 1-18. doi: 10.1016/j.jnutbio.2013.09.001

Wee, J. J., Park, K. M., and Chung, A.-S. (2011). Biological Activities of Ginseng and Its Application to Human Health. Boca Raton FL: Taylor \& Francis. doi: $10.1201 /$ b10787-9

WHO (2016). Global report on diabetes. Geneva: WHO.

WHO expert consultation (2002). Report of the expert committee on the diagnosis and classification of diabetes mellitus. Diabetes Care 25, 5-20.

Xie, J. T., Zhou, Y. P., Dey, L., Attele, A. S., Wu, J. A., Gu, M., et al. (2002). Ginseng berry reduces blood glucose and body weight in $\mathrm{db} / \mathrm{db}$ mice. Phytomedicine 9 , 254-258. doi: 10.1078/0944-7113-00106

Yang, M., Koo, S. I., Song, W. O., and Chun, O. K. (2011). Food matrix affecting anthocyanin bioavailability: review. Curr. Med. Chem. 18, 291-300. doi: $10.2174 / 092986711794088380$

Ye, C., and Driver, J. P. (2016). Suppressors of cytokine signaling in sickness and in health of pancreatic $\beta$-Cells. Front. Immunol. 7:169. doi: 10.3389/fimmu.2016. 00169

Yeh, G. Y., Eisenberg, D. M., Kaptchuk, T. J., and Phillips, R. S. (2003). systematic review of herbs and dietary supplements for glycemic control in diabetes. Diabetes Care 26, 1277-1294. doi: 10.2337/diacare.26.4.1277 
Zarezadeh, M., Baluchnejadmojarad, T., Kiasalari, Z., Afshin-Majd, S., and Roghani, M. (2017). Garlic active constituent s-allyl cysteine protects against lipopolysaccharide-induced cognitive deficits in the rat: possible involved mechanisms. Eur. J. Pharmacol. 795, 13-21. doi: 10.1016/j.ejphar.2016.11.051

Zhang, Y., and Liu, D. (2011). Flavonol kaempferol improves chronic hyperglycemia-impaired pancreatic beta-cell viability and insulin secretory function. Eur. J. Pharmacol. 670, 325-332. doi: 10.1016/j.ejphar.2011.08.011

Zhao, L. Y., Lan, Q. J., Huang, Z. C., Ouyang, L. J., and Zeng, F. H. (2011). Antidiabetic effect of a newly identified component of Opuntia dillenii polysaccharides. Phytomedicine 18, 661-668. doi: 10.1016/j.phymed.2011. 01.001

Zhao, R., Li, Q., and Xiao, B. (2005). Effect of Lycium barbarum polysaccharide on the improvement of insulin resistance in NIDDM rats. Yakugaku Zasshi 125, 981-988. doi: 10.1248/yakushi.125.981
Conflict of Interest Statement: The authors declare that the research was conducted in the absence of any commercial or financial relationships that could be construed as a potential conflict of interest.

The reviewer YW and handling Editor declared their shared affiliation, and the handling Editor states that the process met the standards of a fair and objective review.

Copyright $\odot 2017$ Ota and Ulrih. This is an open-access article distributed under the terms of the Creative Commons Attribution License (CC BY). The use, distribution or reproduction in other forums is permitted, provided the original author(s) or licensor are credited and that the original publication in this journal is cited, in accordance with accepted academic practice. No use, distribution or reproduction is permitted which does not comply with these terms. 